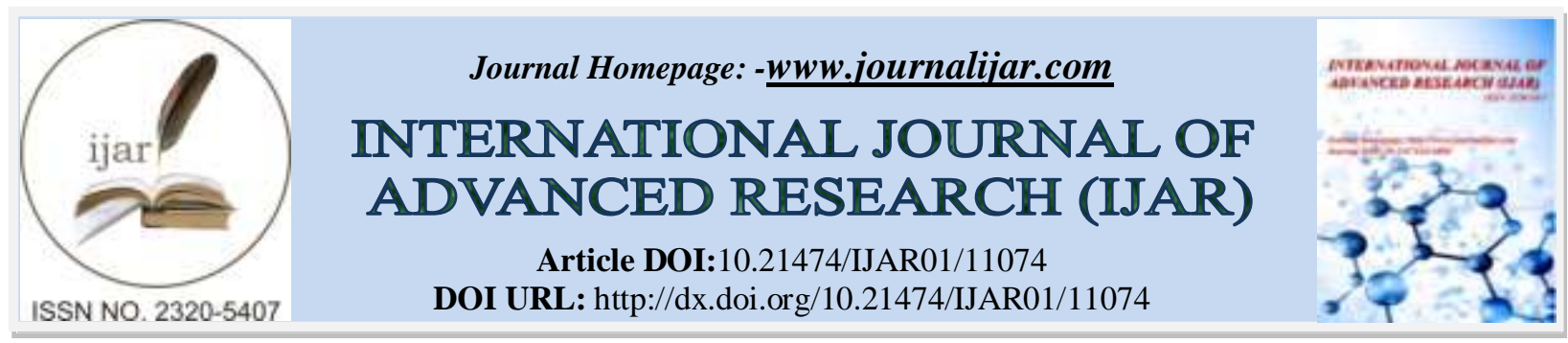

RESEARCH ARTICLE

\title{
LEVEL OF SOCIAL ANXIETY AMONG ADOLESCENCE
}

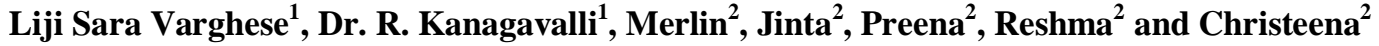

1. Assistant Professor, Faculty of Nursing, Dr.MGR Educational \&Research Institute, Chennai. (Speciality GuideFormerly Working in Zulekha Nursing College), Principal, Zulekha Nursing College, Mangalore.(Research Guide).

2. $4^{\text {th }}$ year Bsc Nursing students.

\section{Manuscript Info}

\section{Manuscript History}

Received: 01 April 2020

Final Accepted: 05 May 2020

Published: June 2020

Key words:-

social Anxiety, Adolescence, Modified

Liebowits Social Anxiety Scale

\begin{abstract}
The students social anxiety is increasing in the world nowadays. More psychotic incidence of students, fatally wounding, kicking etc. Social anxiety is a disabling and treatable disorder with common onset in adolescents. It also a most psychological disorder in school aged children and adolescents world wide. The objectives of the study was to assess the level of social anxiety among adolescence in a selected village, Mangalore.Descriptive research design was used among 60 adolescence with the age group of 12- 18 years and non probabilityconvenient sampling was adopted for the study. The results showed that $20(33.3 \%)$ had mild level of social anxiety and 6(10\%) of them had moderate level of social anxiety.
\end{abstract}

Copy Right, IJAR, 2020,. All rights reserved.

\section{Introduction:-}

Social anxiety is a fear of interaction with other people that bring on self consciousness, feeling of being negatively judged and evaluated and as a result leads to avoidance. It is a disabling and treatable disorder with common onset in adolescence. It is also a most common psychological disorders in school-aged children and adolescents world wide. It is related with their academic impairment and also have co-morbidity of depression.(Approximately 13.3 percent of the general population may meet criteria for social anxiety disorder at some point in their lifetime. In general, males are slightly more disposed to suffer from social anxiety disorder than females.

Social anxiety is identified as a major disorder and it is estimated that world wide one year prevalence of social anxiety is estimated as $4.5 \%$, while life time prevalence appears to be $3.6 \%$.

A study was conducted on social anxiety in adolescence in India among 421 adolescents screened for social anxiety and depression and associated factors with academic impairement, $12.8 \%$ had social anxiety. Another study among higher secondary students revealed that $56.8 \%$ of the population experience social anxiety. A study conducted Tamil Nadu, among 158 adolescents analysis revealed $37.97 \%$ were normal, $33.54 \%$ had moderate social anxiety, $20.25 \%$ had marked social anxiety, $6.97 \%$ had severe social anxiety. It also revealed that females $(78.81 \%)$ had more social anxiety than males $(50.66 \%)$.

Social anxiety disorder involves a persistent intense, chronic fear of being judged by others and of being embarrassed or humiliated by one's own actions. These fears can be triggered by perceived or actual scrutiny from 
others. The fear exceeds normal "shyness" as it leads to excessive social avoidance and substantial social or occupational impairment. Anxiety disorders typically have an age of onset in childhood and adolescence.

Social anxiety is the most common anxiety disorder and the third most common psychiatric disorder, after major depressive disorder and alcohol dependence. The lifetime prevalence estimated for social anxiety vary greatly and range from 0.4 to 20.4 percent in different studies. The epidemiological Catchment Area Survey in 2012 suggested a lifetime prevalence of social anxiety at $2.73 \%$.It was estimated that more than 8,000 individuals from National Comorbidity Survey in 2014 estimated for more than 8,000 individuals that their life time prevalence of social anxiety at $13.3 \%$.

\section{Methodology:-}

Research Approach:

Non-experimental research approach was used for the study.

\section{Research Design:}

Descriptive research design was used to assess the level of social anxiety among adolescence in selected village area, Mangalore(Adyar),Karnataka,India

\section{Population:}

Population of the study was all adolescence within the age group of 12-18 years in selected village area, Mangalore,Karnataka,India

\section{Sample:}

Samples were 60 adolescence within the age group of $12-18$ years.

\section{Sampling Technique:}

Non probability convenient sampling was adopted for the study. There were 100 adolescenceand based on convenient sampling who met inclusive and exclusive criteria 60 samples were chosen.

\section{Criteria for selecting the sample:}

Inclusion Criteria:

1. Adolescence who were willing to participate in the study.

2. Adolescence who were able to read and understand Kannada.

3. Adolescence within the age group of $12-18$ years.

\section{Exclusion Criteria:}

1. Adolescence who were absent at the time of data collection

2. Adolescence who belong to an age less than 12 years and more than 18 years

\section{Description of data collection instrument:}

The instrument consist of two parts.:

\section{Section A:}

Demographic variables such as age, gender, religion, education of parents, occupation of parents, type of family, birth order.

\section{Section B:}

Modified Liebowits social anxiety scale. It consist of 20 items. A score of '3' marks will be given for severe social anxiety, score of ' 2 ' marks will be given for moderate social anxiety, score of ' 1 ' mark will be given for mild social anxiety and score of ' 0 ' will be given for no social anxiety.

\begin{tabular}{|l|l|}
\hline Score & Level of social anxiety \\
\hline $\mathbf{0 - 1 5}$ & None \\
\hline $\mathbf{1 6 - 3 0}$ & Mild \\
\hline $\mathbf{3 1 - 4 5}$ & Moderate \\
\hline
\end{tabular}




\begin{tabular}{|l|l|}
\hline 46-60 & Severe \\
\hline
\end{tabular}

Data Collection Procedure:

Prior to the data collection permission was obtained from concerned authority for conducting the study. Subjects were selected according to selection criteria. Informed verbal consent was obtained from the samples. Modified Liebowitz social anxiety rating scale were administered to 60 adolescents selected from Adyar village area. Health education pamphlet regarding management of social anxiety was administered.

\section{Statistical Analysis:}

Descriptive statistics such as frequency, percentage were used to analyse demographic variables and level of social anxiety.

\section{Results:-}

Section 1: Description of Sample Characteristics

Table1:- Distribution of adolescence on the basis of their age ( $N=60)$.

\begin{tabular}{|l|l|l|l|}
\hline SLNO: & Sample characteristics & Frequency(n) & Percentage(\%) \\
\hline 1. & Age of adoescence & & \\
\hline a & 12-14 years & 20 & 33.3 \\
\hline b & 15-16 years & 20 & 33.3 \\
\hline c & $17-18$ years & 20 & 33.3 \\
\hline $\mathbf{2 .}$ & Gender & & \\
\hline a & Male & 30 & 50 \\
\hline b & Female & 30 & 50 \\
\hline $\mathbf{3}$. & Religion & & \\
\hline a & Hindu & 20 & 33.3 \\
\hline b & Christian & 12 & 20 \\
\hline c & Muslim & 28 & 46.6 \\
\hline $\mathbf{4}$ & Type of family & & \\
\hline a & Nuclear family & 34 & 56.6 \\
\hline b & Joint family & 14 & 23.3 \\
\hline c & Extended family & 12 & 20 \\
\hline $\mathbf{5}$ & Birth order & & \\
\hline a & 1st & 18 & 30 \\
\hline b & 2nd & 20 & 33.3 \\
\hline c & 3rd & 16 & 26.6 \\
\hline d & Others & 6 & 10 \\
\hline
\end{tabular}




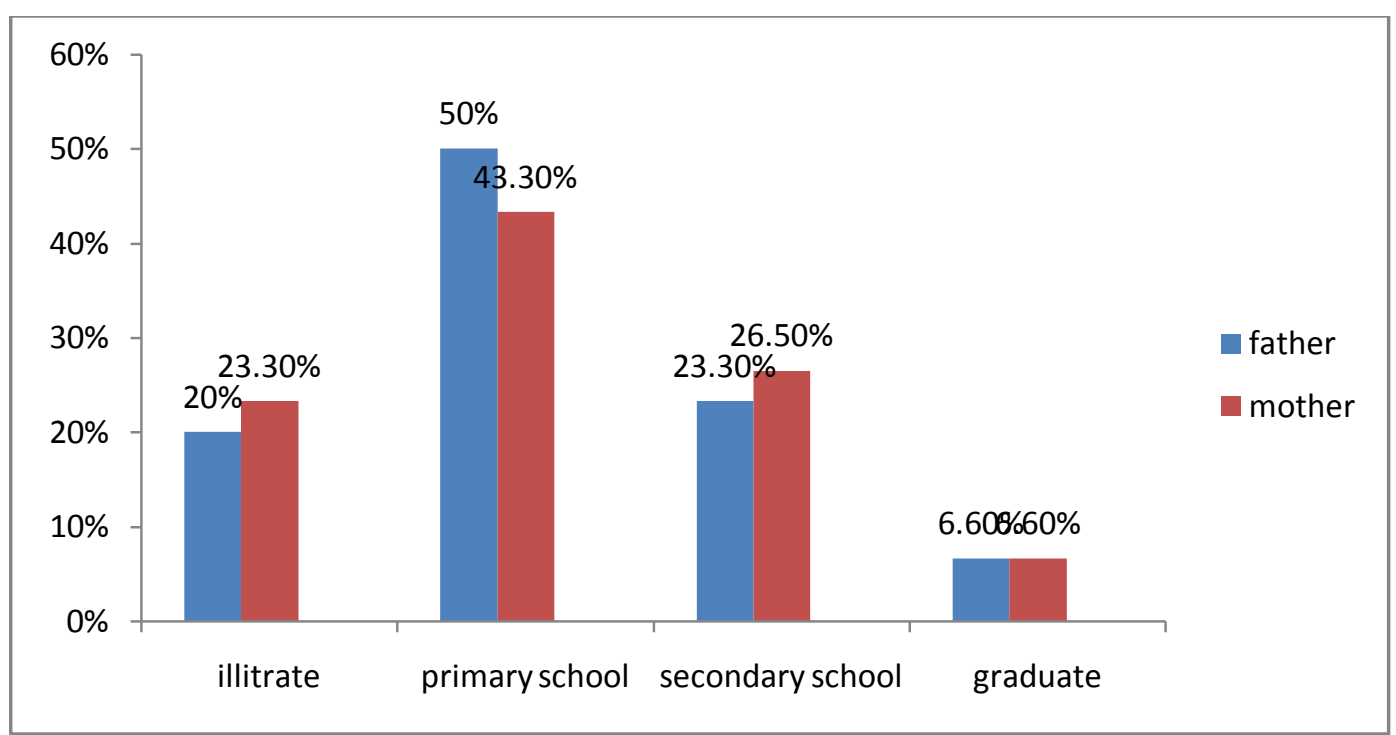

Figure 1:- Distribution of parents according to educational status $(\mathrm{N}=60)$.

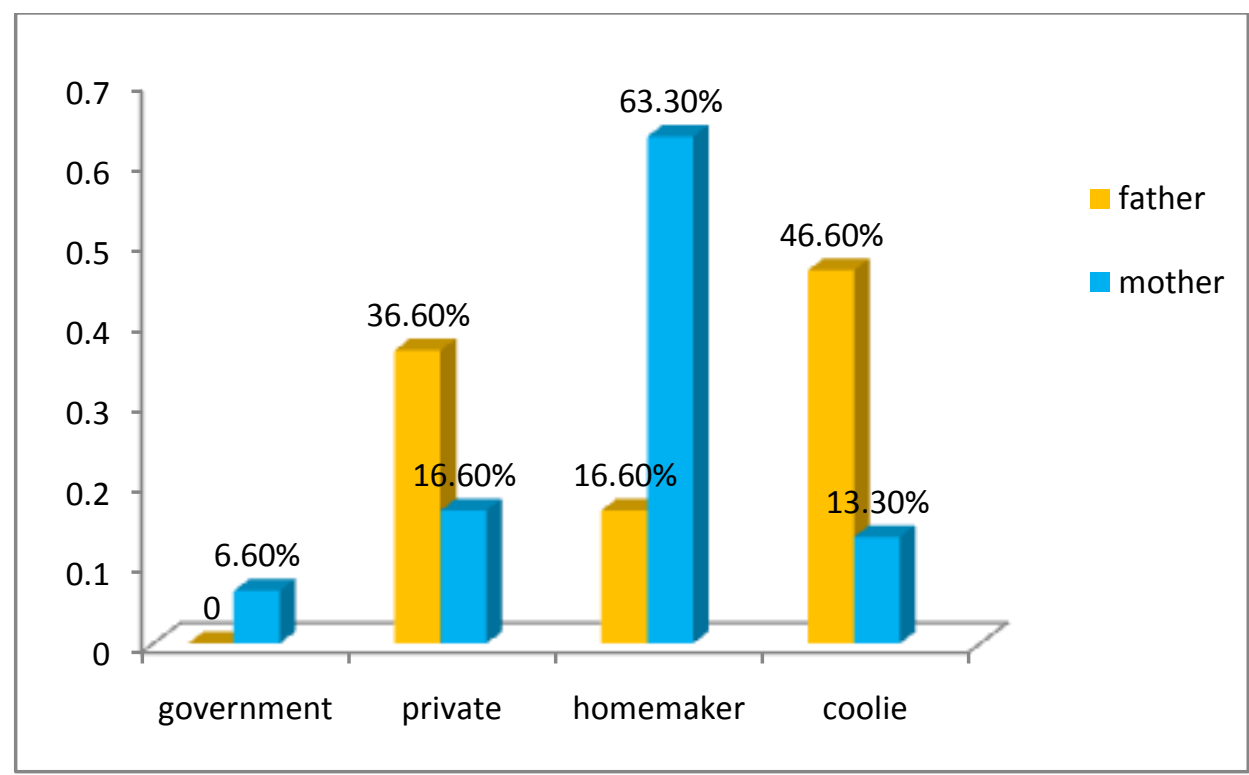

Figure 2:- Distribution of parents according to occupational status(N=60).

Section II: Assess the Level of Social Anxiety Among Adolescence

Table 2:- Showed that 20(33.3\%) had mild level of social anxiety and 6(10\%) of them had moderate level of social anxiety.(N=60).

\begin{tabular}{|l|l|l|l|}
\hline SLNO. & Level of social anxiety & Frequency (n) & Percentage (\%) \\
\hline 1 & None & 34 & 56.6 \\
\hline 2 & Mild & 20 & 33.3 \\
\hline 3 & Moderate & 6 & 10 \\
\hline 4 & Severe & 0 & 0 \\
\hline 5 & Total & 60 & 100 \\
\hline
\end{tabular}

Table 3:- Itemwise Level of Anxiety Among Adolescence.

\begin{tabular}{|l|l|l|l|l|}
\hline $\begin{array}{l}\text { Sln } \\
\text { o. }\end{array}$ & CHARACTERISTICS & MILD & MODERATE & SEVERE \\
\hline
\end{tabular}




\begin{tabular}{|c|c|c|c|c|c|c|c|}
\hline & & Freq(n) & $\%$ & Freq(n) & $\%$ & Freq(n) & $\%$ \\
\hline 1 & Telephoning in public. & 10 & 17 & 2 & 3 & 4 & 7 \\
\hline 2 & Participating in small group. & 14 & 23 & 2 & 3 & 0 & 0 \\
\hline 3 & Eating in public places. & 22 & 37 & 12 & 20 & 2 & 3 \\
\hline 4 & Talking to people in authority. & 22 & 37 & 4 & 7 & 8 & $\begin{array}{l}1 \\
3\end{array}$ \\
\hline 5 & Acting, performing or giving a talk in front of an audience. & 20 & 33 & 14 & 23 & 6 & $\begin{array}{l}1 \\
0\end{array}$ \\
\hline 6 & Going to a party. & 18 & 30 & 8 & 13 & 0 & 0 \\
\hline 7 & Working while being observed. & 16 & 27 & 8 & 13 & 2 & 3 \\
\hline 8 & Writing while being observed. & 18 & 30 & 12 & 20 & 2 & 3 \\
\hline 9 & Calling someone you don't know very well. & 14 & 23 & 4 & 7 & 8 & $\begin{array}{l}1 \\
3\end{array}$ \\
\hline 10 & Talking with people you don't know very well. & 28 & 47 & 6 & 10 & 10 & $\begin{array}{l}1 \\
7\end{array}$ \\
\hline 11 & Meeting strangers. & 22 & 37 & 6 & 10 & 10 & $\begin{array}{l}1 \\
7\end{array}$ \\
\hline 12 & Urinating in a public bathroom. & 14 & 23 & 10 & 17 & 6 & $\begin{array}{l}1 \\
0 \\
\end{array}$ \\
\hline 13 & Entering a room when others are already seated. & 28 & 47 & 4 & 7 & 12 & $\begin{array}{l}2 \\
0 \\
\end{array}$ \\
\hline 14 & Being the center of attention. & 32 & 53 & 6 & 10 & 8 & $\begin{array}{l}1 \\
3\end{array}$ \\
\hline 15 & Speaking up at a meeting. & 14 & 23 & 10 & 17 & 2 & 3 \\
\hline 16 & Taking a test. & 22 & 37 & 4 & 7 & 8 & \begin{tabular}{|l|}
1 \\
3
\end{tabular} \\
\hline 17 & $\begin{array}{l}\text { Expressing a disagreement or disapproval to people you } \\
\text { don't know very well. }\end{array}$ & 26 & 43 & 4 & 7 & 12 & $\begin{array}{l}2 \\
0 \\
\end{array}$ \\
\hline 18 & Looking at people you don't know very well in the eyes. & 20 & 33 & 4 & 7 & 12 & $\begin{array}{l}2 \\
0\end{array}$ \\
\hline 19 & Trying to pick up someone. & 28 & 47 & 10 & 17 & 4 & 7 \\
\hline 20 & Giving a report to a group. & 32 & 53 & 6 & 10 & 8 & $\begin{array}{l}1 \\
3 \\
\end{array}$ \\
\hline
\end{tabular}

The study results showed that $20 \%$ samples had severe anxiety for entering a room when others are being seated,20\% while expressing disagreement or disapproval and $20 \%$ severe anxiety to look strangers

\section{Discussion:-}

An epidemiological study conducted by a department of mental health nursing in Bangalore among 30 samples found that Muslim girls has higher incidence of social anxiety.Majority (31.8\%) of adolescence who belongs to Muslim religion have moderate level of social anxiety and $18.2 \%$ of Hindus have mild level of social anxiety.

Another study conducted to assess the level of social anxiety among adolescence in a selected village area Mangalore concluded that $33.3 \%$ of subjects having mild level of social anxiety, $56.6 \%$ of adolescence were not having social anxiety and $10 \%$ of adolescence with moderate level of social anxiety.

\section{Limitations:}

This study was limited to only one area of the village. So the study cannot be generalized.

This study was limited to 60 samples.

\section{Recommendations:-}

Similar study can be conducted with a large sample size. 
Another study can be conducted to assess factors affecting social anxiety among adolescences

\section{Conclusion:-}

The study concluded that 20(33.3\%) of samples had mild level of social anxiety and 6(10\%) of samples had moderate level of social anxiety.Adolescents should pay attention to reduce the level of social anxiety. The future nurses have a vital role in controlling social anxiety among adolescents. Hence the nurse educators and students nurse come forward and conducted general awareness programme regarding control measures for social anxiety.

\section{References:-}

1. Arlincunice(2016). Prevalance of social anxiety disorder. U Indian j psy . April-June; 26(2): 299-300.

2. Chatterjee.P(2015).Anxiety, adjustment capacity and depression among adolescence in kolkata city. Unpublished doctoral thesis. Kolkata University India.

3. Chorpita B F(2007) .The development of anxiety: the role of control in the early environment. Psycho bull. :124-132.

4. D M fresico, The Leibowtz social anxiety scale(2008). A Comparision of the psychometric properties of self report and clinician administrated formats. Psychological medicine : 125-135.

5. G. Jayashree S. Kasthuri1 J. Sangeetha1 Manjula T.R (2015)..Comparitive study to assess level of social anxiety among adolescents. International journal of psychiatric nursing .Vol 30, 519-532.

6. G K Vankar(2006). Social anxiety in adolescents. Indian journal of psychiatry. 60, 837-844

7. Judle and K Devaki (2016).Assessment of effectiveness of social skill training on social anxiety among adolescent. Journal of health science \& nursing .Vol: 6, 155-166.

8. Kashanni $\mathrm{j}$ and Oravaschel H. A (2010). Community study of anxiety in children and adolescents. American journals of psychiatry .313-318.

9. Rakhee A. S \&AparnaN(2012). Prevalance of anxiety disorders among higher secondary school students. Arch Gen Psy.60,837-844.

10. Russel G (2008). Shared care giving families; An Australian study parenting and child development.12, 126131

11. Susan S .F and Chong M Y(2011). A three year panel study of mental disorders among adolescence in Taiwan .American Journal of psy .344-350.

12. Vimala V and Singh S. Anxiety disorders (2015). Psychological assessment and treatment.NewDelhi;30: 134138. 